\title{
Design and Technological Scheme and Main Parameters of a Re-Placeable Track Unit to the Unit of Traction Class 5
}

\author{
Viktor B. Rykov ${ }^{1}$, Sergey I. Kambulov ${ }^{1}$, and Sergey V. Belousov ${ }^{1,2, *}$ \\ ${ }^{1}$ Agrarian scientific center «Donskoy», department «North-Caucasus scientific-research institute of \\ agricultural mechanization and electrification, Zernograd, Russia \\ ${ }^{2}$ Kuban State Agrarian University named after I.T.Trubilin», Krasnodar, Russia
}

\begin{abstract}
The work highlights the issues of operation of a replaceable caterpillar propeller for a tractor of traction class 5, an analysis of the design of wheeled-caterpillar mobile power facilities is carried out, its positive and negative aspects during operation are described, its detailed justification is given in comparison with wheel propellers, the definitions of normal reactions are drawn up equations of moments, acting relative to the points of application of these reactions on the front and rear propellers, the results of calculating the distribution of pressures along the support branch of the caterpillar bypass are presented.
\end{abstract}

The analysis of the design of wheeled-tracked mobile power units [1,2] shows that the most expedient is the development of a replaceable tracked unit for a wheeled tractor. At the same time, the transition to a track unit should take little time, but in combination with other advantages, such a tractor can have a high economic effect.

Figure 1 shows a variant of a replaceable crawler unit for a Class 5.0 wheeled tractor. It includes a triangular track with an upper drive wheel arrangement, guide wheels and supporting rollers mounted on the longitudinal spar of the crawler truck and a tension device driven by the hydraulic system of the tractor [3].

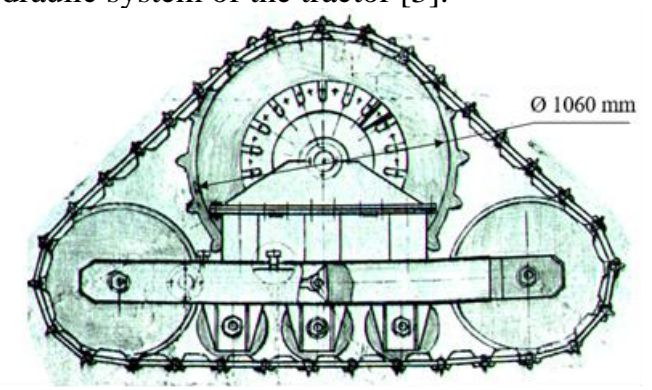

Fig. 1. Replaceable crawler unit

* Corresponding author: sergey_belousov_87@mail.ru 
Such a design and technological scheme of a replaceable crawler unit has a number of advantages in comparison with the generally accepted scheme of the crawler unit, which are as follows:

- since the crawler unit has a hinged connection with the tractor frame and has no other connections with it, the reaction in this hinge is always perpendicular to the supporting section of the track, therefore, with a symmetrical track, the load on all the supporting rollers is the same, which ensures a uniform distribution of specific pressures on the supporting base;

- the triangular track line provides a smaller angle of rotation of the chain elements relative to each other, therefore, less power loss when driving;

- the center of pressure always coincides with the center of the supporting surface of the crawler chain, since this unit is connected to the tractor body with hinges and the reaction is perpendicular to the support base;

- the static tension in the free part of the track chain is less, since this part is directed at an angle to the horizon, therefore, the friction losses should be less in this part;

- the front supporting roller has a large diameter, which implies less losses on soil deformation [4];

- the triangular track chain does not require the installation of supporting rollers, which eliminates the loss of energy due to friction in the bearings and hinges of the track chain when it moves through the supporting rollers.

The radius of the driving wheel is set from the condition that the speed of the crawler unit must be equal to the speed of the tractor:

$$
V=\frac{2 \pi R n_{\partial B}}{i \cdot 60}
$$

On the other hand, the circumferential speed of a driving wheel can be expressed in terms of parameters of the crawler unit:

$$
V=\frac{z l n_{\partial в}}{i \cdot 60}
$$

By equating these speeds, you can determine the radius of the driving wheel:

$$
R=\frac{l z}{2 \pi}=0.53
$$

where $l$ - length of track $(l=0,184 \mathrm{~m}) ; z$ - number of tracks fast-forwarded by the drive wheel in one turn $z=18) ; n_{d r}$ - frequency of the engine crankshaft rotation; $i$ - transmission gear ratio.

Since the replaceable crawler unit must be adapted to the design of a particular tractor, this imposes certain restrictions on its design and technological scheme and parameters of main elements.

In the case of the K-744 tractor, the selected driving wheel radius provides a driving speed of $9-10 \mathrm{~km} / \mathrm{h}$ with a nominal traction effort. The radii of the guide wheels and the length of the supporting surface of the track chain are limited by the layout of the tractor and the possibility of turning.

In this regard, the task is to determine how much these restrictions affect the performance of the replaceable track unit.

The position of the pressure center determines the point of application of normal reactions to the track unit. The distribution of these reactions depends on the design of the track unit and soil conditions in which the tractor operates.

It should be noted that the values of normal reactions significantly affect the traction properties of the tractor, driveability, stability, etc. 
With a uniform movement on the rise, the angle of inclination of which to the horizon is equal to $\alpha$ (Figure 2), the following external forces and reactions act on the tractor [5]:

- $\quad$ tractor weight $G$,

- $\quad$ traction resistance on the piton $P_{p t}$,

- $\quad$ tangential thrust forces of $X_{\kappa}^{n}, X_{\kappa}^{3}$ and resistance forces to rolling of $X_{n}^{n}, X_{n}^{3}$ on each crawler engine;

- $\quad$ resulting normal soil reactions, $Y^{n}, Y^{3}$.

Points of application of these forces are shown in Figure 2.

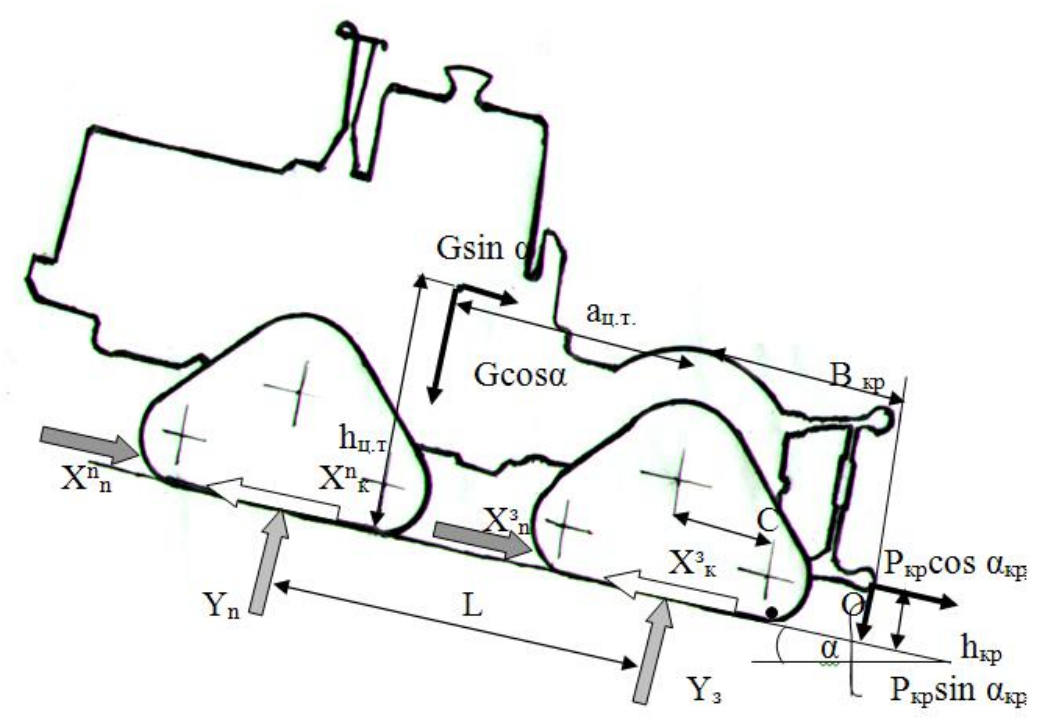

Fig. 2. Scheme of forces acting to the tractor in a longitudinal plane

To determine the normal reactions, the equations of moments acting relative to the points of application of these reactions on the front and rear crawler units are drawn up.

Analysis of these equations shows that the normal reactions on the tractor engines do not remain constant. They vary depending on the traction force on the hook, the angle of elevation or slope, soil conditions, etc.

The installation of a replaceable crawler unit of the proposed design does not change the redistribution of loads between the front and rear crawler units.

In static condition, that is, at $a=0, P_{k p}=0, x_{n}{ }^{n}=0, x_{n}{ }^{3}=0$,

$$
Y_{n}=G \frac{a}{L}, Y_{3}=G \frac{(L-a)}{L}
$$

On the example of the K-744 wheeled tractor, the weight distribution on the front and rear axles is $67.5 \%, 32.5 \%$.

When the tractor is moving on a horizontal section $(\mathrm{a}=0)$ with a nominal traction load $\left(\mathrm{R}_{\mathrm{cr}}=6750\right)$ on the stubble, the normal reactions on the front and rear track units are occurred, respectively.

$$
Y_{n}=7920 \mathrm{~kg}, \quad Y_{3}=6750 \mathrm{~kg}
$$

Thus, when a hook load is applied, the normal reaction to the front track unit decreases, and to the rear one increases, and the normal reactions are equalized (the load distribution on the front and rear axles is $54 \%$ and $46 \%$ ). 


$$
R_{i}^{n}=\frac{y_{n}}{n}=792 \mathrm{~kg}, \quad R_{i}^{3}=675 \mathrm{~kg}
$$

Since the track unit is connected to the tractor frame with hinges and has no other connections with it, and the reaction is always perpendicular to the support base in this hinge, then with a symmetrical position of the rollers relative to the specified hinge, the load on each roller will be the same and will be for the front and rear track units, respectively:

$$
\text { in static under load }
$$

$$
R_{i}^{n}=\frac{y_{n}}{n}=911 \mathrm{~kg}, \quad R_{i}^{3}=440 \mathrm{~kg}
$$

The vertical load transmitted by the supporting part of the track unit to the ground is estimated by the average specific pressure, which is defined as the ratio of the weight $\left(G_{i}\right)$ of the propulsion unit to the area of the supporting part of it.

$$
g_{c p}=\frac{G_{i}}{b L}
$$

where $b$ - width of track line; $L$ - length of the supporting track line.

The actual pressure may differ significantly from the average. We assume that the pressure is transmitted only through the links lying under rollers on a solid base, and then:

$$
g{\frac{G_{i}}{n b t_{\max }}}
$$

where $n$ - number of supporting rollers; $t$ - link step of a track unit.

Taking into account the weight distribution of the K-744 tractor propulsion units, the specific pressure in accordance with the above expressions is:

in static

$$
\begin{aligned}
& g_{c p}^{n}=0.41 \mathrm{~kg} / \mathrm{cm}^{2} ; \quad g_{c p}^{3}=0.20 \mathrm{~kg} / \mathrm{cm}^{2} \\
& g_{\text {max }}^{n}=0.74 \mathrm{~kg} / \mathrm{cm}^{2} ; \quad g_{\text {max }}^{3}=0.36 \mathrm{~kg} / \mathrm{cm}^{2}
\end{aligned}
$$

under load

$$
\begin{aligned}
& g_{c p}^{n}=0.34 \mathrm{~kg} / \mathrm{cm}^{2} ; \quad g_{c p}^{3}=0.31 \mathrm{~kg} / \mathrm{cm}^{2} \\
& g_{\max }^{n}=0.64 \mathrm{~kg} / \mathrm{cm}^{2} ; \quad g_{\max }^{3}=0.55 \mathrm{~kg} / \mathrm{cm}^{2}
\end{aligned}
$$

Here and further, indices mean $n$ - front propulsion unit, $z$ - propulsion unit.

On soft ground the entire crawler line participates in the pressure distribution, and this pressure can be determined by the formula $[4,6]$

$$
g=G_{1} \frac{k e^{x \sqrt{2 k b / T}}}{2 \sqrt{2 k b / T\left(e^{a / 2 \sqrt{2 k b / T}}-1\right)}}
$$

where $G_{l}$ - part of the tractor's weight that falls on the crawler track chain between rollers; $k$ - coefficient of soil crumpling volume; $b$ - track width; $T$ - track tension; $a-$ distance between rollers; $x$ - changeable parameter (track length from origins of coordinates).

From formula 6, it can be seen that the specific pressure depends on the soil state and the design of the replaceable crawler, but in order to use this formula, you need to know the tension of the crawler chain. 
The static tension of the track can be determined from the equilibrium condition of flexible (chain) lines when they sag under their own weight according to the formula of $\mathrm{N}$. N. Belyaev:

$$
T=\frac{m l}{2} \sqrt{1+\frac{l^{2}}{16 f^{2}}}
$$

where $-m$ - specific weight of the track chain; $l$ - length of a free part of the track chain; $f$-sagging of the free part of the track chain.

As expected, the triangular track line provides a slight static tension of the track, which is $116 \mathrm{~kg}$, what significantly reduces internal friction losses in hinges of the free part.

The results of calculations of the pressure distribution along the supporting part of the crawler line according to the formula (6), depending on the operating conditions and parameters of the replaceable crawler unit, are presented in the table 1.

Table 1. Change in specific pressure depending on the parameters of the replaceable crawler unit and operating conditions

\begin{tabular}{|c|c|c|c|c|c|c|c|c|}
\hline \multirow{3}{*}{$\begin{array}{l}\text { Changeable } \\
\text { parameter } \\
(\mathrm{x}), \mathrm{cm}\end{array}$} & \multicolumn{8}{|c|}{ Crawler unit parameters } \\
\hline & \multicolumn{2}{|c|}{$\begin{array}{c}k=4 \\
b=67 \\
a=47,5\end{array}$} & \multicolumn{2}{|c|}{$\begin{array}{c}k=7 \\
b=67 \\
a=47,5\end{array}$} & \multicolumn{2}{|c|}{$\begin{array}{c}k=4 \\
b=42 \\
a=47,5\end{array}$} & \multicolumn{2}{|c|}{$\begin{array}{c}k=4 \\
b=67 \\
a=35\end{array}$} \\
\hline & $\mathrm{g}^{\mathrm{n}}$ & $\mathrm{g}^{3}$ & $\mathrm{~g}^{\mathrm{n}}$ & $\mathrm{g}^{3}$ & $\mathrm{~g}^{\mathrm{n}}$ & $\mathrm{g}^{3}$ & $\mathrm{~g}^{\mathrm{n}}$ & $\mathrm{g}^{3}$ \\
\hline 0 & 0,0003 & 0,0002 & 0,00002 & 0,00001 & 0,002 & 0,002 & 0,002 & 0,002 \\
\hline 10 & 0,015 & 0,011 & 0,004 & 0,0025 & 0,059 & 0,043 & 0,12 & 0,1400 \\
\hline 12 & 0,033 & 0,025 & 0,012 & 0,0074 & 0,11 & 0,084 & 0,27 & ,33 \\
\hline 14 & 0,073 & 0,057 & 0,034 & 0,022 & 0,21 & 0,16 & 0,60 & 0,75 \\
\hline 16 & 0,16 & 0,13 & 0,097 & 0,067 & 0,40 & 0,32 & 1,30 & 1,75 \\
\hline 18 & 0,36 & 0,31 & 0,28 & 0,20 & 0,76 & 1,00 & - & - \\
\hline 20 & 0,81 & 0,71 & 0,81 & 0,60 & 1,45 & 1,18 & - & - \\
\hline
\end{tabular}

Analysis of the tabular data shows that with increasing soil hardness, the pressure on the track chain decreases, therefore, the assumption that on a solid background, the pressure is transmitted only by the links of the track lying under the support rollers is valid.

With an increase in the width of the tracks, the support on it decreases, that is, a wider track contributes to less rutting and less external losses.

An increase in the number of support rollers leads to the fact that the pressure is perceived by all the links of the supporting section of the track.

The uneven distribution of pressures along the length of the track supporting surface increases the resistance to tractor movement by $19-28 \%$. In this regard, it can serve as a characteristic of a crawler unit and is determined by the formula:

$$
\xi=\frac{a}{2} \sqrt{\frac{2 k b}{T}}
$$

\section{Conclusion}

For the calculation options presented in the table, the unevenness of the pressure distribution is $9.5,12.5,7.5$, and 7.0 , respectively, i.e. the best is the track with the parameters $b=67 \mathrm{~cm}$ and $a=35 \mathrm{~cm}$ with the radius of the drive wheel $\mathrm{R}=0.53 \mathrm{~m}$.

\section{References}


1. Rykov V.B. Mechanical and technological justification of technical tools and aggregates for tillage in the conditions of arid agriculture in the south of Russia: Abstract of $\mathrm{PhD}$ thesis in Engineering: 05.20.01 / V.B. Rykov. - Zernograd, 2001. - 426 p.

2. Kambulov S.I. Mechanical and technological grounds of increasing the level of agricultural aggregates functioning / S.I. Kambulov. - Rostov-on-Don: Publishing house «Terra Print», 2006. - 304 p.

3. Rykov V.B. Replaceable track unit and its interaction with a supporting base / V.B. Rykov, S.I. Kambulov, Achievements of science and AIC technology. - 2005. - № 9. P. 29-30.

4. Guskov V.V. Optimal parameters of agricultural tracks, V.V. Guskov. - M.: Mechanical engineering, 1966. - $193 \mathrm{p}$.

5. Kutkov G.M. Tractors and automobiles. Theory and technological properties / G.M. Kutkov. - М.: Колос, 2004. - 504 p.

6. Zabavnikov N.A. Fundamentals of the theory of transport tracked vehicles / N.A. Zabavnikov. - M.: Mechanical engineering, 1968. 